\title{
Analysis on Sediment Nutrients and Alkaline Phosphatase Activity of Wetland in Hulunbeier Grassland
}

\author{
Jing $\mathrm{HE}^{1}$, Derong $\mathrm{SU}^{1, *}$, Shihai $\mathrm{LV}^{2}$, Zhirong ZHENG ${ }^{2}$, Shengxing $\mathrm{YE}^{2}$ and Zhaoyan DIAO² \\ ${ }^{1}$ Research Center of Grassland Resources and Ecology, Beijing Forestry University, Beijng 100083, China \\ ${ }^{2}$ State Environmental Protection Key Laboratory of Regional Eco-process and Function Assessment, Chinese Research Academy of \\ Environmental Sciences (CRAES), Beijing 100012, China
}

\begin{abstract}
The dynamic changes in sediment nutrients, alkaline phosphatase activity and the relationships between them and wetland in Hulunbeier Grassland in different sites were studied. The results show that with the time change, $\mathrm{pH}$ value of wetlands sediment in three sites showed increasing trend. And organic matter of wetlands sediment in three sites showed first decreased slightly first and then gradually increased trend; Total nitrogen of wetlands sediment in three sites presented a slightly decreased trend. Total phosphorus of wetlands sediment in three sites showed a gradually decreased trend. The alkaline phosphatase activity of wetlands sediment in Hulun Lakes and Yimin River had the largest increase in July and then decreased while it was reached maximum in August and then decreased in September in Hui River. Correlation analysis results showed that the alkaline phosphatase activity of wetlands sediment was positively correlated with organic carbon, total phosphorus and $\mathrm{pH}$ value while it was significantly positively correlated with total nitrogen.
\end{abstract}

\section{Introduction}

Eutrophication has become a hot environmental issue of global concern. It can cause many problems, include rapid reproduction of algae and other plankton, decline of dissolved oxygen, deterioration of water quality, large number deaths of fish and other aquatic organisms.

Numerous studies show that eutrophication limiting factor is phosphorus [1-3]. Sources of phosphorus in water can be divided into exogenous phosphorus and endogenous phosphorus. When the exogenous phosphorus has been effectively controlled, the endogenous phosphorus becomes a major source of water phosphorus load. As well known endogenous phosphorus mainly caused by the release of sediment. Therefore, the study of sediment phosphorus release laws is very important to eutrophication. Our wetland resources become more and more precious, especially in Hulunbeier city.

The previous research about wetland phosphorus source in Hulunbeier Grassland focuses on exogenous phosphorus [4] in a lack of depth and conclusive research results about sediment.

In this study, wetlands sediment from there different sites were collected to test physicochemical properties, nutrient status and alkaline phosphatase activity. Hope to explore the relationship between nutrients and alkaline phosphatase activity of wetlands sediment in Hulunbeier Grassland.

\section{Materials and Methods}

\subsection{Study Area}

Hulunbeier Grassland located in Hulunbeier city of southwest Inner Mongolia Autonomous and adjacent Russia and Mongolia north and west respectively. Location: longitude $115^{\circ} 31$ ' $121^{\circ} 35^{\prime} \mathrm{N}$, latitude $47^{\circ}$ 20 ' $50^{\circ} 51^{\prime} \mathrm{E}$, altitude $500 \sim 800 \mathrm{~m}$. The climate in this area is continental monsoon climate with an annual average rainfall of $250 \sim 400 \mathrm{~mm}$ and an annual average temperature of $-3 \sim 0{ }^{\circ} \mathrm{C}$, the accumulated temperature $\geqslant$ $10{ }^{\circ} \mathrm{C}$ of $1900{ }^{\circ} \mathrm{C} \sim 2200{ }^{\circ} \mathrm{C}$.

\subsection{Sampling regime and Sediment analysis}

The sediments were collected on July 15, 2015 - July 17, 2015, August 18, 2015 - August 20, 2015 and September 9, 2015 - September 11, 2015, respectively. We have set fifteen sampling sites in Hulun Lake, Yiming River and Hui River and each site choose five point to collect surface sediment of $0 \sim 10 \mathrm{~cm}$ depth. Mixed five points in each site then taken back to the lab. The samples were used to test soil phosphatase activity and soil nutrients after dried and sifted.

The Alkaline phosphatase activities of sediments were assayed by benzene disodium phosphate colorimetric method [5]. Sediments organic matters were tested by potassium dichromate volumetric - external heating method and sediments soil total nitrogen were determined by Kjeldahl nitrogen method. Sediments total phosphorus were used $\mathrm{H}_{2} \mathrm{SO}_{4}-\mathrm{HCLO}_{4}$ digestion method while $\mathrm{pH}$ value were analysed by soil $\mathrm{pH}$ meter measurement with water ratio of 1.0: 2.5 [6].

\subsection{Data Analysis}

Excel 2010 and SAS software were used for statistical data analysis and multiple comparisons.

\section{Results and Analysis}

\subsection{Wetland sediment nutrient changes during July to September of 2015}

By determination of wetland sediment nutrients found that there is a great difference of different types of nutrients in different months of $\mathrm{pH}$, organic matter, total nitrogen, total phosphorus nutrient (Table 1). With the time change, $\mathrm{pH}$ value of wetlands sediment in three sites 
showed increasing trend. And organic matter of wetlands sediment in three sites showed first decreased slightly first and then gradually increased trend; Total nitrogen of wetlands sediment in three sites presented a slightly decreased trend. Total phosphorus of wetlands sediment in three sites showed a gradually decreased trend.

\subsection{Alkaline Phosphatase activity changes during July to September of 2015}

Alkaline phosphatase enzyme as an important enzyme plays a key role in the phosphorus cycle of river. It has a key role in the sediments overlying water biological phosphorus release process because it can catalyze the hydrolysis reaction and shift reactions of phosphatase groups, so the sediment insoluble organic phosphorus (OP) hydrolysis can be dissolved into inorganic phosphorus (IP) while the organic phosphate dissolved into inorganic phosphorus[7]. An increasing number of studies have confirmed that the enzyme has important functions in phosphorus cycling in aquatic ecosystems and the sediment ecosystem take microbial as main body, it also plays an important role in organic matter mineralization process [8].

The alkaline phosphatase activity of wetlands sediment showed different trends from three sites. In Hulun Lakes and Yimin River it had the largest increase in July and then decreased while it was reached maximum in August and then decreased in September in Hui River(Figure 1). This may be affected by water temperature and phosphorus types of sediment [9].

\subsection{Correlation analysis of nutrients and sediment alkaline phosphatise activities}

Through correlation analysis we conclude that the total phosphorus was significantly positively correlated with total nitrogen while the total nitrogen was significantly positively correlated with $\mathrm{pH}$ value.

In addition, the alkaline phosphatase activity of wetlands sediment was positively correlated with organic carbon, total phosphorus and $\mathrm{pH}$ value while it was significantly positively correlated with total nitrogen (Table 2). This result was consistent with the consequence found in Maqu wetland [10].

\section{Conclusions}

With the time change, $\mathrm{pH}$ value of wetlands sediment in three sites showed increasing trend. And organic matter of wetlands sediment in three sites showed first decreased slightly first and then gradually increased trend; Total nitrogen of wetlands sediment in three sites presented a slightly decreased trend. Total phosphorus of wetlands sediment in three sites showed a gradually decreased trend.

The alkaline phosphatase activity of wetlands sediment in Hulun Lakes and Yimin River was reached biggest in July and then decreased while it was reached maximum in August and then decreased in September in Hui River.
The alkaline phosphatase activity of wetlands sediment was positively correlated with organic carbon, total phosphorus and $\mathrm{pH}$ value while it was significantly positively correlated with total nitrogen.

\section{Acknowledgements}

This work was financially supported by Specific Research on Public Service of Environmental Protection in China (No. 201509040). In addition, thanks staff from Hui River national nature reserve offer help. 
Table 1. Dynamic Change of Wetland sediment nutrients

\begin{tabular}{|c|c|c|c|c|}
\hline Sediment Nutrients & Month & Hulun Lake & Yimin River & Hui River \\
\hline \multirow{3}{*}{$\mathrm{pH}$} & 7 & $7.1100 \pm 0.0200 \mathrm{~b}$ & $7.3267 \pm 0.0473 \mathrm{a}$ & $6.6800 \pm 0.1311 \mathrm{c}$ \\
\cline { 2 - 5 } & 8 & $7.7833 \pm 0.0153 \mathrm{a}$ & $7.7167 \pm 0.0321 \mathrm{~b}$ & $7.5633 \pm 0.0153 \mathrm{c}$ \\
\cline { 2 - 5 } & 9 & $7.8000 \pm 0.0300 \mathrm{c}$ & $7.9067 \pm 0.0058 \mathrm{a}$ & $7.8567 \pm 0.0155 \mathrm{~b}$ \\
\cline { 2 - 5 } & 7 & $3.1434 \pm 0.0179 \mathrm{a}$ & $2.5185 \pm 0.2154 \mathrm{~b}$ & $1.2190 \pm 0.7046 \mathrm{c}$ \\
\cline { 2 - 5 } & 8 & $1.6039 \pm 0.2000 \mathrm{~b}$ & $1.3442 \pm 0.1829 \mathrm{~b}$ & $3.2606 \pm 0.3547 \mathrm{a}$ \\
\hline \multirow{3}{*}{ TC\% } & 9 & $1.3983 \pm 0.0575 \mathrm{c}$ & $1.8525 \pm 0.1535 \mathrm{~b}$ & $2.7294 \pm 0.2410 \mathrm{a}$ \\
\cline { 2 - 5 } & 7 & $0.0740 \pm 0.0142 \mathrm{c}$ & $0.1458 \pm 0.0073 \mathrm{~b}$ & $0.3042 \pm 0.0168 \mathrm{a}$ \\
\cline { 2 - 5 } & 8 & $0.0836 \pm 0.0046 \mathrm{~b}$ & $0.0895 \pm 0.0084 \mathrm{~b}$ & $0.1933 \pm 0.0128 \mathrm{a}$ \\
\hline \multirow{3}{*}{ TP\% } & 9 & $0.0631 \pm 0.0029 \mathrm{c}$ & $0.0745 \pm 0.0034 \mathrm{~b}$ & $0.1947 \pm 0.0042 \mathrm{a}$ \\
\cline { 2 - 5 } & 7 & $0.0904 \pm 0.0030 \mathrm{a}$ & $0.0622 \pm 0.0153 \mathrm{~b}$ & $0.0375 \pm 0.0027 \mathrm{c}$ \\
\cline { 2 - 5 } & 8 & $0.0517 \pm 0.0064 \mathrm{~b}$ & $0.0140 \pm 0.0038 \mathrm{c}$ & $0.1057 \pm 0.0098 \mathrm{a}$ \\
\hline
\end{tabular}

Note: Letters mean significant at 0.05 level.

Dynamic of alkaline phosphatase activity of wetland sediment ir. Hulunbeier Grassland

口 Jul.

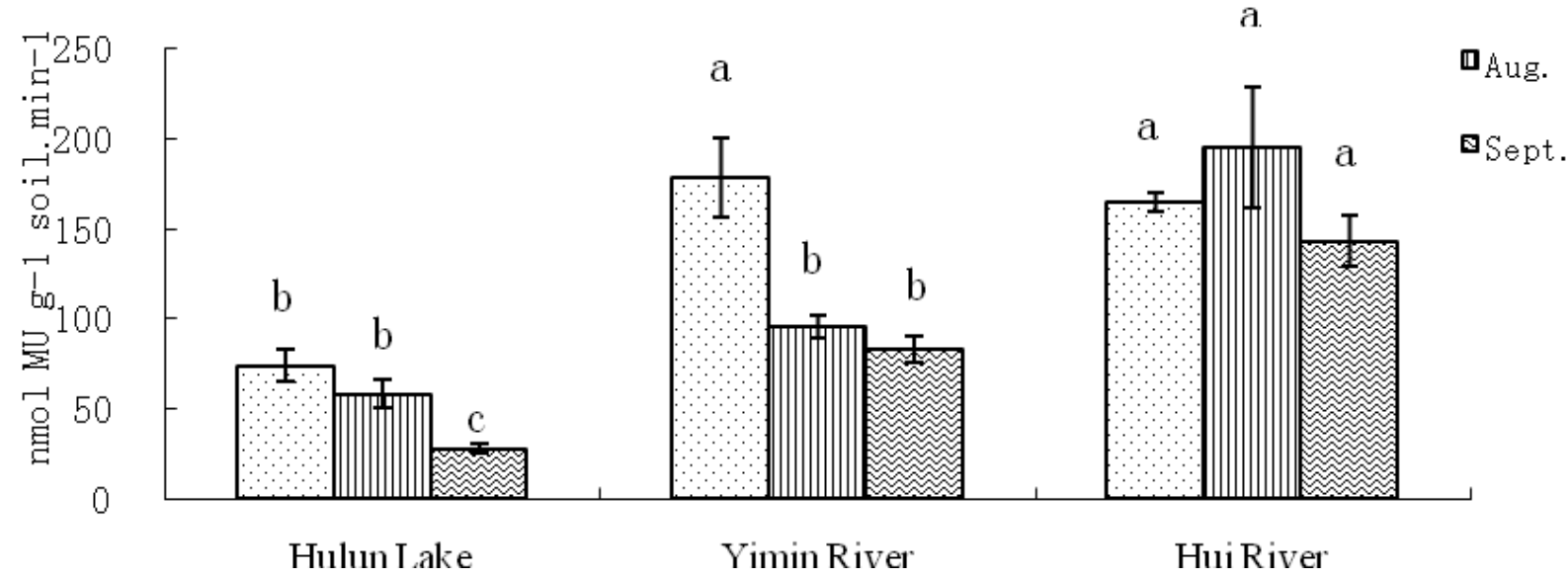

Figure 1. Dynamic alkaline phosphatase activity of wetland sediment in Hulunbeier Grassland

Table 2. Correlation analysis of nutrients and sediment alkaline phosphatase activity

\begin{tabular}{cccccc}
\hline & TC\% & TN\% & TP\% & Ph & ALP(nmolMU.g soil.min $^{-1}$ ) \\
\hline TC\% & 1 & & & & \\
TN\% & 0.5936 & 1 & & & \\
TP\% & $0.0001^{* *}$ & 0.2744 & 1 & & 1 \\
Ph & 0.424 & $0.0007^{* *}$ & 0.2468 & 1 & 1 \\
ALP(nmolMU.g soil.min $^{-1}$ ) & $0.0133^{*}$ & $<.0001^{* *}$ & $0.0293^{*}$ & $0.0348^{*}$ & \\
\hline
\end{tabular}




\section{References}

[1] Andrew N. Sharpley, S. C. Chapra, R. Wedepohl, J. T. Sims, T. C. Daniel, K. R. Reddy, JEQ, 23,437451(1994)

[2] G.FRED LEE, Role of phosphorus in eutrophication and diffuse source control (WRPP, Great Brita, 1973)

[3] ISEMANNK, FR, 26, 253-269(1990)

[4] Ahui Chen, Weiping Li, Linghong YU, Zhenyu YIN, Manquan GUI, Dongmei MIAO, EPC, 37,3438(2015)

[5] Lanpo ZHAO, Yan JIANG, CGSS, 3, 138-141(1986)

[6] Shidan BAO, the method of soil agro-chemistry analysis (CAP, Beijing, 2000)

[7] Wenjue HUANG, Yangen WU, Jinhua SHU, JLS, 10, 83-90(1998)

[8] Huanxin WENG, Yachao QIN, Xiangwei SUN, Hailiang DONG, Xianghua CHEN, ECSS, 73, 501509(2007)

[9] Zhe ZHANG, Characteristic of Alkaline Phosphatase Activity of Sediment in Lakes and Its Ecological Effect on Phosphorus (HBUST, Shijiazhuang, 2013)

[10] Shiquan NIU, Junfeng LI, Tingting YANG, Wenyan DA, Jianwen YANG, Yingzhi NING, Jian YAO, JGG, 5,1022-1029(2010) 